\title{
Erratum to: Purification and characterization of a lectin from the starfish Asterias amurensis
}

\author{
Yoshitaka Imamichi · Yoshihiro Yokoyama
}

Published online: 31 October 2013

(C) The Japanese Society of Fisheries Science 2013

\section{Erratum to: Fish Sci}

DOI 10.1007/s12562-013-0667-9

The article cited above was incorrectly categorized. The correct category is Original Article, not Review Article, with a subject area of Chemistry and Biochemistry.

The online version of the original article can be found under doi:10.1007/s12562-013-0667-9.

Y. Imamichi

Department of Biochemistry, Faculty of Medical Sciences,

University of Fukui, Fukui 910-1193, Japan

Y. Yokoyama $(\bowtie)$

Laboratory of Food Chemistry, Department of Marine

Bioscience, Faculty of Marine Bioscience, Fukui Prefectural

University, Fukui 917-0003, Japan

e-mail: yokoyama@fpu.ac.jp 